\title{
PENGARUH KINERJA KEUANGAN DAERAH TERHADAP BELANJA MODAL (STUDI PADA PEMERINTAH DAERAH KABUPATEN/KOTA SE-JAWA BARAT PERIODE TAHUN ANGGARAN 2012-2017)
}

\author{
${ }^{1}$ Irma Novita \\ ${ }^{2}$ Nunung Nurhasanah \\ Pasca Sarjana Manajemen Universitas Singaperbangsa Karawang \\ denisyara@gmail.com, \\ nnurhasanah.jihan@gmail.com
}

\begin{abstract}
The research aims to know, analyze and explain the area's financial performance as measured by dependency ratio, PAD effectiveness ratio, efficiency ratio, fiscal space ratio, SILPA financing rate ratio and $B U M D$ contribution ratio as well as its effect on the shopping ratio, both partially and simultaneously towards the allocation of capital expenditure in APBD. The research population is the entire local government district/city in West Java in 2010-2017. The results showed that the average local government district/city in West Java in 2010-2017 has a capital expenditure ratio and low BUMD contribution ratio, fiscal space ratio and SILPA medium financing rate ratio, with dependence rate to high central government and still less efficient in spending management, but it has high PAD effectiveness.
\end{abstract}

Key Words: Keywords: dependency ratio, PAD effectiveness ratio, efficiency ratio, fiscal space ratio, SILPA financing rate ratio, BUMD contribution ratio, shopping ratio

\begin{abstract}
ABSTRAK
Penelitian ini bertujuan untuk mengetahui, menganalisis dan menjelaskan kinerja keuangan daerah yang diukur dengan rasio ketergantungan, rasio efektivitas PAD, rasio efisiensi, rasio ruang fiskal, rasio tingkat pembiayaan silpa dan rasio kontribusi BUMD serta pengaruhnya terhadap rasio belanja, baik secara parsial maupun simultan terhadap alokasi belanja modal dalam APBD. Populasi penelitian adalah seluruh pemerintah daerah kabupaten/kota se Jawa Barat pada tahun 2010 -2017. Hasil penelitian menunjukkan bahwa rata-rata pemerintah daerah kabupaten/kota se Jawa Barat pada tahun 2010 -2017 memiliki rasio belanja modal dan rasio kontribusi BUMD yang rendah, rasio ruang fiskal dan rasio tingkat pembiayaan Silpa sedang, dengan tingkat ketergantungan kepada pemerintah pusat tinggi dan masih kurang efisien dalam pengelolaan belanja, namun memiliki efektivitas PAD tinggi.
\end{abstract}

Kata Kunci: Rasio ketergantungan, Rasio efektivitas PAD, Rasio efisiensi, Rasio ruang fiskal, Rasio tingkat pembiayaan silpa, Rasio kontribusi BUMD, Rasio Belanja 


\section{PENDAHULUAN}

Adanya pergeseran pola belanja dalam pemerintah daerah khususnya belanja modal untuk pelayanan publik memicu permasalahan tentang sejauh mana besarnya pendapatan daerah mempengaruhi pola belanja pemerintah daerah khususnya belanja modal untuk pelayanan publik. Beberapa studi empiris yang telah dilakukan menunjukkan bahwa upaya pemerintah daerah untuk meningkatkan penerimaan daerah telah menimbulkan distorsi pasar dan high cost economy (Saad, 2003, dikutip Hafidh, $2013: 4$ ).

Selain itu, upaya-upaya yang dilakukan pemerintah daerah untuk meningkatkan penerimaan daerah kurang diikuti upaya untuk meningkatkan pelayanan publik (Halim, 2012).

Untuk mengukur kinerja suatu organisasi (termasuk di sektor publik), berbagai metodelogi dan instrument telah dimanfaatkan, seperti Balanced Scorecard, Total Performance Scorecard, Total Quality Management, dan lain sebagainya. Ragamnya metode pengukuran kinerja tersebut menunjukkan kecendrungan perhatian yang tinggi terhadap peningkatan kualitas kinerja instansi pemerintah, khususnya dalam memberikan pelayanan kepada masyarakat. Meskipun demikian penerapan metode-metode tersebut harus mengakomodasikan lingkungan pemerintah daerah, agar mendapatkan hasil yang memiliki validitas tinggi dan tidak terjadi kesalahan pengukuran kinerja.

Salah satu alat ukur yang dapat digunakan untuk menganalisis kinerja pemerintah daerah dalam mengelola keuangan daerahnya adalah melakukan analisis rasio keuangan terhadap APBD yang telah ditetapkan dan dilaksanakan (Halim, 2012: 231).

Kinerja keuangan dapat digunakan sebagai ukuran keberhasilan daerah otonom dalam menyelenggarakan otonomi daerah. Dengan melihat kinerja keuangan kita dapat mengetahui akuntabilitas dari para pemangku kekuasaan, dimana setiap rupiah uang publik harus dipertanggungjawabkan kepada masyarakat yang telah memberikan uangnya untuk membiayai pembangunan dan roda pemerintahan (Mahmudi, 2010).

Berdasarkan data APBD Kabupaten/Kota se-Jawa Barat Tahun Anggaran 2016, diketahui bahwa rata-rata rasio ketergantungan daerah berada pada angka 75,60 atau kategori tinggi. Artinya bahwa untuk membiayai pembangunan di daerahnya, Kabupaten/Kota se-Jawa Barat masih sangat tergantung pada dana transfer dari Pemerintah Pusat/Provinsi, sebagaimana digambarkan dalam grafik berikut ini : 
Gambar 1.3. Rasio Ketergantungan Kabupaten/Kota Se-Jawa Barat Tahun Anggaran 2016

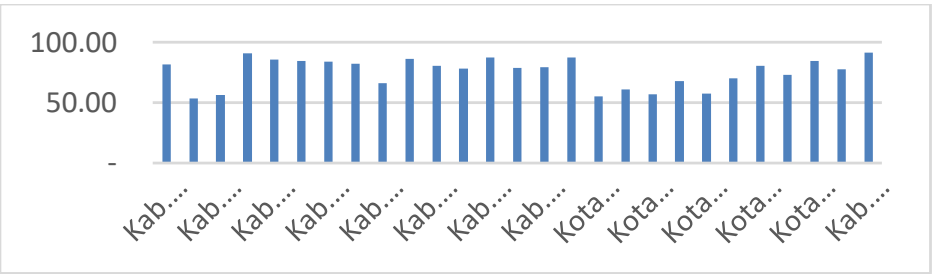

Sumber : data diolah, peneliti, 2019

Selain itu, data APBD Kabupaten/Kota se-Jawa Barat Tahun Anggaran 2016, berdasarkan grafik di bawah ini menunjukkan bahwa rata-rata rasio efisensi daerah berada pada angka 107,37 atau kategori tinggi. Artinya bahwa realisasi belanja daerah masih lebih besar dari pada realisasi pendapatan, hal ini menunjukkan bahwa hampir seluruh Kabupaten/Kota seJawa Barat masih mengalami defisit anggaran, meskipun di sisi lain, defisit ini masih bisa diatasi dengan adanya pembiayaan, baik yang bersumber dari Sisa Lebih Perhitungan Anggaran Tahun sebelumnya, Dana Cadangan, maupun pinjaman daerah.

\section{Gambar 1.4. Rasio Efisiensi Kabupaten/Kota Se-Jawa Barat Tahun Anggaran 2016}

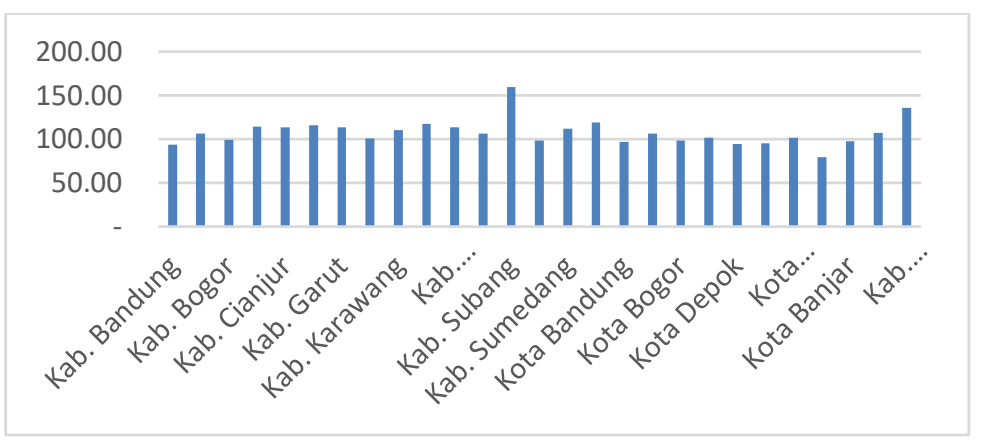

Sumber : data diolah, peneliti, 2019

\section{METODE PENELITIAN}

\section{Jenis Penelitian}

Penelitian ini merupakan penelitian kualitatif dengan pendekatan deskriptif Kualitatif. Pada penelitian ini, setelah peneliti mengumpulkan data dalam bentuk pengamatan dan pencatatan secara sistematis terhadap gejala atau fenomena yang ada pada objek penelitian. Kasiram (2008) Pengertian penelitian kuantitatif adalah metode penelitian yang menggunakan proses data-data yang berupa 66 | B u a n I $1 \mathrm{~m} \mathrm{u}$ 
Irma Novita, Nunung Nurhasanah

Vol 4 No 2

ISSN : 2541-6995

E ISSN : 2580-5517

angka sebagai alat menganalisis dan melakukan kajian penelitian, terutama mengenai apa yang sudah di teliti.

\section{Waktu dan Tempat Penelitian}

Pemerintah daerah Kabupaten/kota se-Jawa Barat periode tahun anggaran 2012-2017.

\section{Target/Subjek Penelitian}

Penelitian ini merupakan studi kasus mengenai pengelolaan keuangan daerah yang dilakukan dengan menganalisis kinerja keuangan pemerintah daerah kabupaten dan kota se-Provinsi Jawa Barat berdasarkan data Laporan Keuangan Daerah selama kurun waktu 6 (enam) tahun, dari tahun 2012 sampai dengan 2017 yang merupakan data-data sekunder yang diperoleh dari website resmi maupun langsung dari instansi Pengelola Keuangan Daerah dan pengaruhnya terhadap rasio belanja modal dalam APBD.

\section{Prosedur Penelitian}

Desain penelitian merupakan sederatan proses, langkah-langkah, ataupun alur penelitian yang dimulai dari awal seperti studi pendahuluan sampai dengan akhir seperti hasil yang berkaitan dengan salah satunya pengambilan kesimpulan atas hipotesis dalam penelitian tersebut. Berdasarkan data Laporan Keuangan Daerah selama kurun waktu 6 (enam) tahun, dari tahun 2012 sampai dengan 2017 yang merupakan data-data sekunder yang diperoleh dari website resmi maupun langsung dari instansi Pengelola Keuangan Daerah dan pengaruhnya terhadap rasio belanja modal dalam APBD.

\section{Data, Instrumen, dan Teknik Pengumpulan Data}

Observasi, yaitu cara dan teknik pengumpulan data dengan melakukan pengamatan dan pencatatan secara sistematis terhadap gejala atau fenomena yang ada pada objek penelitian. Dokumentasi, yaitu data sekunder yang disimpan dalam bentuk dokumen atau file (catatan konvensional maupun elektronik), buku, tulisan, laporan, notulen rapat, majalah, surat kabar, dan lain sebagainya. Metode pengumpulan data dokumentasi digunakan dalam rangka memenuhi data atau informasi yang diperlukan untuk kepentingan variabel penelitian yang telah didesain sebelumnya. Pengumpulan data dilakukan dengan cara mempelajari data-data yang berupa catatan-catatan atau dokumendokumen yang berkaitan dengan pembahasan dalam penelitian.

\section{Teknik Analisis Data}

Dalam penyajiannya, penelitian ini menggunakan metode deskriptif dan verifikatif. Metode deskriptif bertujuan untuk memperoleh gambaran mengenai kondisi kinerja keuangan Daerah di 
Irma Novita, Nunung Nurhasanah

Vol 4 No 2

ISSN : 2541-6995

E ISSN : 2580-5517

Kabupaten/kota se- Jawa Barat, dengan menggunakan indikator Rasio Ketergantungan, Rasio Efektivitas, Rasio Ruang Fiskal, Rasio Efisiensi, Rasio Pembiayaan Silpa, dan Rasio Kontribusi BUMD. Sedangkan metode verfikatif digunakan untuk menguji pengaruh kinerja keuangan secara parsial terhadap pengalokasian belanja modal dalam APBD di Kabupaten/kota se- Jawa Barat.

Seluruh kabupaten/kota dijadikan sampel dalam penelitian, karena penelitian ini tidak dimaksudkan untuk menggeneralisir permasalahan, melainkan untuk menguji pengaruh antar variabel yang diteliti.

\section{HASIL PENELITIAN DAN PEMBAHASAN}

\section{Hasil}

Penelitian ini menguji pengaruh rasio kinerja keuangan daerah terhadap rasio belanja modal pemerintah daerah tahun 2012-2017 dan menggunakan software eviews 8.0 dengan data panel. Sebelum dilakukan pengujian hipotesis, terlebih dahulu dilakukan pengujian asumsi klasik. Pengujian asumsi klasik yang dilakukan dalam penelitian ini terdiri dari uji normalitas uji multikolinieritas, dan uji autokorelasi.

\section{Pengujian Normalitas Jarque-Berra}

Untuk melihat apakah residu atau eror yang terdapat pada variabel independen terdistribusi secara normal atau tidak, digunakan pengujian Normalitas Jarque Berra (Winarno, 2011). Nilai JarqueBerra dalam penelitian ini adalah 0,39 dengan tingkat probabilitas 0,82 sehingga residu dalam variabel independen terdistribusi normal yang dapat dilihat pada gambar berikut ini :

\section{Gambar 4.1. Hasil pengujian Normalitas}

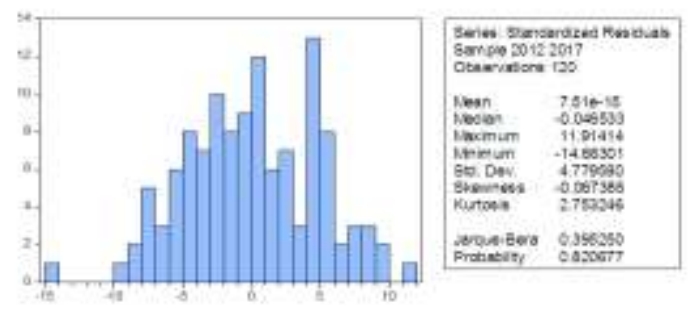

\section{Pengujian Multikolinearitas}

Pengujian multikolinearitas antar semua variabel dalam penelitian ini menggunakan korelasi

Pearson yang dapat dilihat pada Tabel 4.4. Dalam penelitian ini tidak terdapat multikolinearitas 
Irma Novita, Nunung Nurhasanah

Vol 4 No 2

ISSN : 2541-6995

E ISSN : 2580-5517

yang dapat dilihat dari nilai hubungan antar variabel independen lebih kecil dari 0.8.

Tabel 4.4 Korelasi Antar Variabel

\begin{tabular}{|c|c|c|c|c|}
\hline & RBM & REFE REFI & RTPS & RKB \\
\hline$\overline{\mathrm{RBM}}$ & 1.00000 & & & \\
\hline RK & -0.61119 & 1.00000 & & \\
\hline REFE & -0.03426 & 0.041441 .00000 & & \\
\hline REFI & -0.13724 & $0.11005-0.055451 .00000$ & & \\
\hline RRF & 0.59971 & $-0.790900 .00745-0.29811$ & 1.00000 & \\
\hline RTPS & 0.68913 & $-0.614830 .12196-0.12480$ & 0.623531 .00000 & \\
\hline RKB & -0.23098 & $0.383080 .14353-0.03242$ & $-0.29670-0.08895$ & 1.00000 \\
\hline
\end{tabular}

Sumber : data diolah eviews, 2019

\section{Uji Heteroskedastisitas}

Pengujian heteroskedastistas pada penelitian ini menggunakan pengujian White General Heteroskedasticty. Dari hasil pengujian heteroskedastisitas pada tabel 4.5 tidak terdapat heteroskedastisitas di dalam model karena nilai $O b s^{*} R$-Square sebesar 38,84 dengan probability 0,065 lebih besar dari $p$ value 0,05 .

Tabel 4.5Pengujian Heteroskedastisitas

Heteroskedasticity Test: White

\begin{tabular}{lrlr}
\hline F-statistik & 1.631247 & Prob. F(27,92) & 0.0449 \\
Obs*R-squared & 38.84959 & Prob. Chi-Square(27) & 0.0654 \\
Scaled explained SS 30.19909 & Prob. Chi-Square(27) & 0.3053 \\
\hline
\end{tabular}

Sumber : data diolah eviews, 2019

\section{Uji Autokorelasi}

Pengujian Autokorelasi pada penelitian ini menggunakan pengujian Watson Test. Hasil pengujian terlihat pada tabel 4.6 Nilai durbin watson pada tabel sebesar 0.923224. Pada tabel durbin watson dengan jumlah sampel 120 dan variabel 6 nilai DL 1,61642 dan DU 1.78964.

Dari data diatas dapat disimpulkan bahwa Nilai DW (0.923224) lebih kecil dari DL $(1,61642)$ maka terdapat autokerelasi poitif dan nilai 4-DW (4-0.923224) lebih besar dari nila DU $(1,78964)$ tidak 69 | B u a n a I $1 \mathrm{~m}$ u 
terdapat nilai autokerelasi negatif.

\section{Pengujian Regresi Berganda}

Hasil pengujian regresi yang disajikan pada tabel 4.6. telah melalui pengujian asumsi klasik

Tabel 4.6. Hasil Pengujian Hipotesis Model Regresi

$$
\begin{gathered}
\mathrm{RBM}_{\mathrm{it}}=\alpha_{0}+\alpha_{1} \mathrm{RK}_{\mathrm{it}}+\alpha_{2} \mathrm{REFE}_{\mathrm{it}}+\alpha_{3} \mathrm{REFI}_{\mathrm{it}}+\alpha_{4} \mathrm{RRF}_{\mathrm{it}}+\alpha_{5} \\
\mathrm{RTPS}_{\mathrm{it}}+\alpha_{5} \mathrm{RKB}_{\mathrm{it}}+\varepsilon
\end{gathered}
$$

\begin{tabular}{|c|c|c|}
\hline Variabel & Coefficient & Prob. \\
\hline $\mathrm{C}$ & 27.01043 & $0.0383 * * *$ \\
\hline RK & -0.114394 & $0.1425 *$ \\
\hline REFE & -0.023129 & 0.2112 \\
\hline REFI & -0.032726 & 0.6958 \\
\hline $\mathrm{RRF}$ & 0.072210 & 0.3070 \\
\hline RTPS & 0.517807 & $0.0000 * * *$ \\
\hline RKB & -0.213287 & 0.2872 \\
\hline R-squared & 0.550179 & \\
\hline Adjusted R-squared & 0.526295 & \\
\hline F-statistik & 4.904830 & \\
\hline Durbin-Watson Stat & 0.923224 & \\
\hline Prob(F-statistik) & $0.0000 * * *$ & \\
\hline
\end{tabular}

Variabel Dependen: RBM= Rasio Belanja Modal; Variabel

Independen: $\mathbf{R K}=$ Rasio Ketergantungan; REFE = Rasio

Efektifitas; REFI = Rasio Efisiensi; RRF= Rasio Ruang Fiskal;

RTPS= Rasio Tingkat Pembiayaan Silpa; RKB = Rasio

Kontribusi BUMD;

Level Signifikansi : *** sig pada level 5\%,** sig pada level 10\%, dan * sig pada level $20 \%$. 


\section{Pengujian Koefisien Determinasi}

Pengujian koefisien determinasi digunakan untuk mengukur kemampuan model dalam menerangkan variabel dependen. Pengujian regresi OLS pada model pertama, kedua dan ketiga menggunakan koefisien determinasi Adjusted (R-Squared). Berdasarkan tabel 4.5. ditemukan bahwa nilai koefisien determinasi yang dilihat dari Adjusted R-Squared sebesar 0.526295. Hasil ini menunjukkan bahwa variabel independen kemungkinan mempengaruhi variabel dependen sebesar $52.63 \%$. Sedangkan sisanya sebesar $47.37 \%$ dijelaskan oleh variabel lain yang tidak diteliti dalam penelitian ini.

\section{Pembahasan}

\section{Rasio Belanja Modal}

Rata-rata rasio belanja modal Kabupaten/Kota se-Jawa Barat masih rendah. Pada tahun 2012 sebesar 18,88, tahun 2013 sebesar 20,97, tahun 2014 sebesar 19,29, tahun 2015 sebesar 17,78, tahun 2016 sebesar 20,31 dan tahun 2017 sebesar 17,33 sebagaimana ditunjukkan gambar 4.1.

Dari keseluruhan data yang diamati, Rasio belanja modal tertinggi adalah Kota Depok pada Tahun 2013 sebesar 36,58 dan terendah adalah Kota Tasikmalaya pada Tahun 2017 sebesar 7,53.

\section{Rasio Ketergantungan (RK)}

Hasil penelitian sebagaimana gambar 4.2 memperlihatkan bahwa rata-rata rasio ketergantungan pada tahun 2012 sebesar 84,15, tahun 2013 sebesar 82,71, tahun 2014 sebesar 79,09, tahun 2015 sebesar 78,39, tahun 2016 sebesar 78,01 dan tahun 2017 sebesar 73,64. Hal ini menunjukkan bahwa pemerintah Kabupaten/Kota seJawa Barat masih memiliki tingkat ketergantungan yang tinggi khususnya dalam hal pendanaan pembangunan terhadap Pemerintah Pusat.

\section{Rasio Efektivitas (REFE)}

Dari hasil penelitian diketahui bahwa Rata-rata Pemerintah Daerah Kabupaten/Kota se Jawa Barat pada Tahun 2012-2017 memiliki nilai Rasio Efektivitas (REFE) yang tinggi. Sebagaimana diperlihatkan pada gambar 4.4, dimana rata-rata rasio Efektivitas pada tahun 2012 sebesar 133,42, tahun 2013 sebesar 122,56, tahun 2014 sebesar 133,24, tahun 2015 sebesar 109,97, tahun 2016 sebesar 102,67 dan tahun 2017 sebesar 124,44.

\section{Rasio Efisiensi (REFI)}

\section{1 | B u a n a I $1 \mathrm{~m}$ u}


Irma Novita, Nunung Nurhasanah

Vol 4 No 2

ISSN : 2541-6995

E ISSN : 2580-5517

Data rata-rata rasio Efisiensi pada tahun 2012 sebesar 95,95, tahun 2013 sebesar 98,60, tahun 2014 sebesar 95,07, tahun 2015 sebesar 97,43, tahun 2016 sebesar 103,42 dan tahun 2017 sebesar 104,09.

\section{Rasio Ruang Fiskal (RRF)}

Data rata-rata rasio Ruang Fiskal pada tahun 2012 sebesar 31,69, tahun 2013 sebesar 33,06, tahun 2014 sebesar 34,50, tahun 2015 sebesar 33,43, tahun 2016 sebesar 35,20 dan tahun 2017 sebesar 38,50 .

\section{Rasio Tingkat Pembiayaan Silpa (RTPS)}

Data rata-rata rasio Pemanfaatan SIlpa pada tahun 2012 sebesar 8,68, tahun 2013 sebesar 10,17, tahun 2014 sebesar 9,92, tahun 2015 sebesar 12,90, tahun 2016 sebesar 12,58 dan tahun 2017 sebesar 7,05 .

\section{Rasio Kontribusi BUMD (RKB)}

Dalam penelitian ini, Rasio Kontribusi BUMD yang diukur dengan berdasarkan Realisasi Laba BUMD terhadap Realisasi Pendapatan Asli Daerah sebagaimana gambar 4.8 menunjukkan bahwa data rata-rata Rasio Kontribusi BUMD pada tahun 2012 sebesar 3,61, tahun 2013 sebesar 3,39, tahun 2014 sebesar 2,43, tahun 2015 sebesar 2,39, tahun 2016 sebesar 2,41 dan tahun 2017 sebesar 1,92 atau dengan kata lain, rata-rata Rasio Kontribusi BUMD masih berada pada kategori rendah.

\section{Pengaruh Rasio Efektifitas PAD terhadap Alokasi Belanja Modal pada APBD}

Hipotesis ini ditolak berdasarkan hasil pengujian yang menunjukkan bahwa rasio efektifitas berpengaruh negatif dan tidak signifikan terhadap alokasi belanja modal. Artinya, kenaikan atau penurunan rasio efektivitas tidak memberikan dampak yang berarti terhadap penurunan atau kenaikan alokasi belanja modal.

\section{Pengaruh Rasio Efisiensi PAD terhadap Alokasi Belanja Modal pada APBD.}

Hipotesis H3 mengatakan bahwa terdapat pengaruh rasio efsisensi PAD terhadap Alokasi Belanja Modal pada APBD. Hasil pengujian menunjukkan bahwa rasio efisiensi berpengaruh negatif dan tidak signifikan terhadap alokasi belanja modal, hal ini berarti bahwa kenaikan atau penurunan rasio efisiensi tidak memberikan dampak yang berarti terhadap penurunan atau kenaikan alokasi belanja modal.

\section{Pengaruh Rasio Ruang Fiskal terhadap Alokasi Belanja Modal pada APBD}

Hipotesis H4 mengatakan bahwa terdapat pengaruh Rasio Ruang Fiskal terhadap Alokasi Belanja Modal pada APBD. Namun, hasil penelitian ini menunjukkan bahwa rasio ruang fiscal tidak 
Irma Novita, Nunung Nurhasanah

Vol 4 No 2

ISSN : 2541-6995

E ISSN : 2580-5517

berpengaruh terhadap alokasi belanja modal dalam APBD, padahal seharusnya, belanja modal menjadi belanja prioritas dalam perencanaan dan penganggaran APBD

\section{Pengaruh Rasio Tingkat Pembiayaan Silpa terhadap Alokasi Belanja Modal pada APBD}

Hipotesis H5 mengatakan bahwa terdapat pengaruh rasio tingkat pembiayaan Silpa terhadap Alokasi Belanja Modal pada APBD, dan hasil pengujian menerima hipotesis ini dan menunjukkan bahwa rasio tingkat pembiayaan Silpa berpengaruh positif dan signifikan terhadap alokasi belanja modal, yang berarti semakin tinggi rasio tingkat pembiayaan Silpa maka alokasi belanja modal semakin tinggi tingkat pembiayaan Silpa.

\section{Pengaruh Rasio Kontribusi BUMD terhadap Alokasi Belanja Modal pada APBD}

Hipotesis H6 mengatakan bahwa terdapat pengaruh rasio kontribusi BUMD terhadap Alokasi Belanja Modal pada APBD. Hasil pengujian menunjukan bahwa rasio kontribusi BUMD berpengaruh negatif dan tidak signifikan terhadap alokasi belanja modal, yang berarti bahwa kenaikan atau penurunan rasio kontribusi BUMD tidak memberikan dampak yang berarti terhadap penurunan atau kenaikan alokasi belanja modal.

Pengaruh Rasio Kinerja Keuangan Daerah secara simultan terhadap Alokasi Belanja Modal pada APBD

Hipotesis H7 mengatakan bahwa terdapat pengaruh Rasio Kinerja Keuangan Daerah secara simultan terhadap alokasi Belanja Modal pada APBD. Hasil pengujian menunjukkan bahwa variabel independen kemungkinan mempengaruhi variabel dependen sebesar 52.63\%. Sedangkan sisanya sebesar $47.37 \%$ dijelaskan oleh variabel lain yang tidak diteliti dalam penelitian ini.

\section{KESIMPULAN DAN IMPLIKASI}

\section{Kesimpulan}

Berdasarkan hasil penelitian dapat dikemukakan kesimpulan sebagai berikut

1. Kinerja Keuangan Daerah Pemerintah Kabupaten/Kota se-Jawa Barat pada Tahun Anggaran 2012 - 2017, dapat digambarkan sebagai berikut:

a. rasio rata-rata belanja modal berada pada kategori rendah;

b. tingkat ketergantungan terhadap Pemerintah Pusat, khususnya dalam hal pendanaan pembangunan pada kategori tinggi; 
Irma Novita, Nunung Nurhasanah

Vol 4 No 2

ISSN : 2541-6995

E ISSN : 2580-5517

c. rasio efektivitas pada kategori tingggi, atau memiliki kinerja yang sangat baik dalam hal pencapaian realisasi Pendapatan Asli Daerah;

d. rasio efisiensi pada kategori tinggi, yang menunjukkan bahwa dalam hal pengelolaan belanja di daerahnya, masih kurang efisien;

e. Rasio rata-rata Ruang Fiskal pada kategori sedang;

f. Rasio rata-rata tingkat pembiayaan Silpa pada kategori sedang;

g. Rasio Rata-rata Kontribusi BUMD pada kategori rendah.

2. Rasio Ketergantungan yang menunjukkan tingkat ketergantungan pemerintah daerah terhadap pembiayaan pemerintah pusat dalam hal pendanaan pembangunan berpengaruh negatif namun tidak signifikan terhadap rasio belanja modal.

3. Rasio efektivitas berpengaruh negatif tapi tidak signifikan terhadap rasio belanja modal. Hal ini bertentangan dengan hasil penelitian sebelumnya, bahwa rasio efektivitas berpengaruh positif dan signifikan terhadao rasio belanja modal. Kondisi ini dimungkinkan mengingat sejak tahun 2014, Pemerintah pusat mengeluarkan kebijakan yang mengharuskan Pemeritnah Daerah untuk mengalokasikan Dana Bagi Hasil kepada Pemerintah Desa, sehingga anggaran yang seharusnya dialokasikan untuk belanja modal, dialihkan untuk memenuhi ketentuan tersebut.

4. Rasio Efisiensi berpengaruh negatif namun tidak signifikan terhadap rasio belanja modal

5. Rasio Ruang Fiskal berpengaruh positif namun tidak signifikan terhadap rasio belanja modal

6. Rasio Tingkat Pembiayaan Silpa berpengaruh positif dan signifikan terhadap rasio belanja modal. Hal ini menunjukkan bahwa tinggi nya nilai Silpa akan meningkatkan alokasi belanja modal pada APBD

7. Rasio kontribusi BUMD berpengaruh negatif namun tidak signifikan terhadap rasio belanja modal.

8. Kinerja Keuangan Daerah secara simultan berpengaruh terhadap alokasi Belanja Modal pada APBD. Hal ini menunjukkan bahwa apabila kinerja keuangan daerah baik, maka alokasi belanja modal pada APBD akan meningkat.

\section{Implikasi}

74|B u a n I $1 \mathrm{mu}$ 
Irma Novita, Nunung Nurhasanah

Vol 4 No 2

ISSN : 2541-6995

E ISSN : 2580-5517

1. Penelitian ini menunjukkan bahwa terdapat pengaruh kinerja keuangan daerah terhadap alokasi belanja modal pada ABBD sehingga dapat menambah referensi untuk pengembangan penelitian berikutnya.

2. Terdapat banyak keterbatasan dalam penelitian ini, antara lain penggunaan data sekunder yang sangat dominan, sehingga bagi peneliti selanjutnya, diharapkan dapat menggabungkan penggunaan data sekunder dan data primer melalui wawancar untuk memperkuat analisis penelitian. Selain itu, penggunaan rasio untuk mengukur kinerja keuangan daerah maupun penambahan variabel dependen juga mungkin bisa lebih dikembangkan.

\section{DAFTAR PUSTAKA}

Abdullah, Syukriy \& Abdul Halim. 2003. Pengaruh Dana AlokasiUmum (DAU) dan Pendapatan Asli Daerah (PAD) terhadap Belanja Pemerintah Daerah Studi Kasus Kabupaten/Kota di Jawa dan Bali. Simposium Nasional Akuntansi VI. Yogyakarta : 1140-115.

Adhiantoko, Hony. 2013. Analisis Kinerja Keuangan Pemerintah Kabupaten Blora Tahun 20072011.Skripsi. Universitas Negeri Yogyakarta.

http://eprints.uny.ac.id/17846/1/Skripsi\%20.pdf diakses 7 April 2019

Affandi, Azhar. 2015. Pendekatan Penelitian Kuantitatif. Karawang :Unsika

Ardhini \& Sri Handayani. 2011. Pengaruh Rasio Keuangan Daerah terhadap Belanja Modal untuk Pelayanan Publik dalam Perspektif Teori Keagenan (Studi Pada Kabupaten dan Kota di Jawa Tengah). Undergraduate Thesis, Universitas Diponegoro, Semarang.

http://eprints.undip.ac.id/30929/1/JURNAL.pdf diakses 7 April 2019

Batafor, Gregorius Gehi. 2011. Evaluasi Kinerja Keuangan dan Tingkat Kesejahteraan

Masyarakat Kabupaten Lembata - Provinsi NTT. Universitas Udayana.

(https://docplayer.info/387876-Evaluasi-kinerja-keuangan-dan-tingkat-kesejahteraan-masyarakatkabupaten-lembata-provinsi-ntt.html diakses 23 Februari 2017

Direktorat Jenderal Anggaran, Kementerian Keuangan RI. 2012. Belanja Modal dan Pengeluaran Investasi Pemerintah. Kementerian Keuangan Republik Indonesia.

http://www.anggaran.depkeu.go.id/dja/edef-konten-view.asp?id=908 . Diakses pada 9 April 2019. Direktorat Jenderal Perimbangan Keuangan, Kementerian Keuangan RI. 2011. Deskripsi dan Analisis APBD 2011. 
Irma Novita, Nunung Nurhasanah

Vol 4 No 2

ISSN : 2541-6995

E ISSN : 2580-5517

http://www.djpk.kemenkeu.go.id/wp-

content/uploads/2016/01/deskripsi_dan_analisis_APBD_2011_a.pdf diakses pada 9 April 2019

Direktorat Jenderal Perimbangan Keuangan, Kementerian Keuangan RI. 2013. Potret APBD TA 2013. http://www.djpk.kemenkeu.go.id/wp-content/uploads/2016/01/POTRET-APBD-TA2013.pdf diakses pada 9 April 2019

Direktorat Jenderal Perimbangan Keuangan, Kementerian Keuangan RI. 2012. PROFIL APBD TA 2012. http://www.djpk.kemenkeu.go.id/wp-content/uploads/2016/01/Profil_APBD_TA2012.pdf diakses pada 9 April 2019

Direktorat Jenderal Perimbangan Keuangan. 2012. Profil APBD 2012.

http://www.djpk.depkeu.go.id/wp-content/uploads/2016/01/Profil_APBD_TA2012.pdf,diunduh pada 7 Mei 2019

Dora, Juliani. 2017. Analisis Kinerja Keuangan Daerah Pemkot Jogyakarta th 2010-2014.

http://repository.usd.ac.id/12237/2/132114125_full.pdf diakses 7 April 2019

Hafidh, Aula Ahmad. 2013. Analisis Rasio Keuangan Daerah dalam Mempengaruhi Belanja

Modal Publik bagi Pertumbuhan Ekonomi. Jurnal Penelitian Humaniora Vol. 18 No.2, Oktober 2013

Halim, Abdul. 2012. Akuntansi Sektor Publik: Akuntansi Keuangan Daerah. Jakarta : Salemba Empat.

Halim, Abdul. 2012. Pengelolaan Keuangan Daerah. Edisi Ketiga. Yogyakarta : UPP STIM YKPN

Hasan, Misbah \& Yenti Nurhidayat. 2017. Laporan Anmgalisis Anggaran Daerah 2016 Hasil Penelitian di 70 Kabupaten/Kota. Jakarta : Seknas FITRA dan The Ford Foundation (FF)

Hidayat, Mochamad Fajar. 2013. Analisis Pengaruh Kinerja Keuangan Daerah Terhadap Alokasi Belanja Modal (Studi Pada Kabupaten Dan Kota Di Jawa Timur). FEB Universitas Brawijaya Malang.

Kadek Martini \& A.A.N.B. Dwirandra. 2015. Pengaruh Kinerja Keuangan Daerah di Provinsi Bali. ISSN: 2302-8556. E-Jurnal Akuntansi Universitas Udayana 10.2 (2015):426-443. Kawedar. 2008. Pendekatan Penganggaran Daerah dan Akuntansi Keuangan Daerah, Jilid II UNDIP - Semarang, 
Irma Novita, Nunung Nurhasanah

Vol 4 No 2

ISSN : 2541-6995

E ISSN : 2580-5517

Kurni Adi Suwandi \& Afrizal, Tahar. 2015. Pengaruh Kinerja Keuangan Terhadap Pertumbuhan

Ekonomi Daerah Dengan Alokasi Belanja Modal Sebagai Variabel Intervening.

Universitas Muhammadiyah Yogyakarta.

http://journal.trunojoyo.ac.id/infestasi/article/view/1127/957 diakses 7 April 2019

Mahmudi. 2010. Manajemen Keuangan Daerah. Jakarta : Erlangga.

Mahmudi. 2010. Analisis Laporan Keuangan Pemerintah Daerah. Yogyakarta: UPP STIM

YKPN

Mardiasmo. 2002. Otonomi dan Manajemen Keuangan Daerah. Yogyakarta: Penerbit Andi.

Mahsun, Mohamad. 2018. Pengukuran Kinerja Sektor Publik. Yogyakarta : BPFE

Seknas Fitra. 2017. Laporan Analisis Anggaran Daerah 2016 Hasil Penelitian di 70

Kabupaten/Kota. https://seknasfitra.org/wp-content/uploads/2017/03/LBA-2016.pdf diakses pada

9 April 2019

Siregar, Baldric. 2017. Akuntansi Sektor Publik. Yogyakarta : UPP STIM YKPN

Sularso, Havid. 2011. Pengaruh Kinerja Keuangan Terhadap Alokasi Modal dan Pertumbuhan

Ekonomi Kabupaten/Kota di Jawa Tengah. FE Unsoed. Jurnal Media Riset Akuntansi, Vol.1, No.2, Agustus 2011, hal. 109-124.

Wulandari, Anita. 2001. Kemampuan Keuangan Daerah di Kota Jambi Dalam Melaksanakan

Otonomi Daerah. Jurnal Kebijakan dan Administrasi Publik, Kemampuan Keuangan

Daerah (Vol. 5, No. 2). November

Republik Indonesia. 2004. Undang-Undang Nomor 33 Tahun 2004 tentang Perimbangan

Keuangan antara Pemerintah Pusat dan Pemerintahan Daerah.

Republik Indonesia. 2005. Peraturan Pemerintah Nomor 55 Tahun 2005 tentang Dana

Perimbangan.

Republik Indonesia. 2005. Peraturan Pemerintah Nomor 58 Tahun 2005 tentang Pengelolaan

Keuangan Daerah .

Republik Indonesia. 2014. Undang-Undang Nomor 23 Tahun 2014 tentang Pemerintahan Daerah.

Menteri Dalam Negeri 2006. Peraturan Menteri Dalam Negeri Nomor 13 Tahun 2006 tentang

Pedoman Pengelolaan Keuangan Daerah Menteri Dalam Negeri. 2013.

77 | B u a n a I $1 \mathrm{~m} \mathrm{u}$ 